\title{
Retraction Note to: Potential Start Codon Targeted (SCoT) and Interretrotransposon Amplified Polymorphism (IRAP) Markers for Evaluation of Genetic Diversity and Conservation of Wild Pistacia Species Population
}

\author{
Karim Sorkheh $^{1} \cdot$ Nazanin Amirbakhtiar $^{2} \cdot$ Sezai Ercisli $^{3}$ \\ Published online: 10 November 2017 \\ (c) Springer Science+Business Media, LLC, part of Springer Nature 2017
}

\section{Retraction Note to: Biochem Genet (2016) 54:368-387 https://doi.org/10.1007/s10528-016-9725-1}

This article has been retracted by the Publisher in agreement with the Editor-inChief, because it contains portions of writings on the same topic already published and without sufficient attribution to these earlier works being given. The principal authors of the paper acknowledged that text from background sources was mistakenly used in this article without proper reference to the original source. Upon investigation carried out according to the Committee on Publication Ethics guidelines, it has been found that the authors have duplicated or rephrased parts from other articles of which the main sources are the following:

Alikhani L, Rahmani MS, Shabanian N, Badakhshan H, Khadivi-Khub A (2014) Genetic variability and structure of Quercus brantii assessed by ISSR, IRAP and SCoT markers. Gene 552:176-183

Iranjo P, Nabati Ahmadi D, Sorkheh K, Rajabi Memeari H, Ercisli S (2016) Genetic diversity and phylogenetic relationships between and within wild Pistacia species populations and implications for its conservation. J For Res 27: 685-697

Shanjani PS, Mardi M, Pazouki L, Hagidimitriou M, Avanzato D, Pirseyedi SM, Ghaffari MR, Khayam Nekoui SM (2009) Analysis of the molecular variation

The original article can be found online at https://doi.org/10.1007/s10528-016-9725-1.

Karim Sorkheh

karimsorkheh@gmail.com

1 Department of Agronomy and Plant Breeding, Faculty of Agriculture, Shahid Chamran University of Ahvaz, P.O.Box 61355/144, Ahvaz, Iran

2 Department of seed and Plant Improvement, Agricultural \& Natural Resources Research and Education Center, P.O.Box 61333-3341, Ahvaz, Iran

3 Department of Horticulture, Agricultural Faculty, Ataturk University, 25240 Erzurum, Turkey 
between and within cultivated and wild Pistacia species using AFLPs. Tree Genet Genomes 5:447-458

Luo C, He XH, Chen H, Ou SJ, Gao MP (2010) Analysis of diversity and relationships among mango cultivars using start codon targeted (SCoT) markers. Biochem Syst Ecol 38:1176-1184

In a commitment to scientific integrity we decided to retract the article. 